This document was prepared in conjunction with work accomplished under Contract No. DE-AC09-96SR18500 with the U.S. Department of Energy.

This work was prepared under an agreement with and funded by the U.S. Government. Neither the U. S. Government or its employees, nor any of its contractors, subcontractors or their employees, makes any express or implied: 1 . warranty or assumes any legal liability for the accuracy, completeness, or for the use or results of such use of any information, product, or process disclosed; or 2 . representation that such use or results of such use would not infringe privately owned rights; or 3 . endorsement or recommendation of any specifically identified commercial product, process, or service. Any views and opinions of authors expressed in this work do not necessarily state or reflect those of the United States Government, or its contractors, or subcontractors. 


\title{
INEXPENSIVE, OFF-THE-SHELF HYBRID MICROWAVE SYSTEM
}

\author{
R.T. Walters*, P. Burket, J. H. Scogin, IV
}

Savannah River National Laboratory,PO Box 616,Aiken, SC,29808, tom.walters@srnl.doe.gov

\begin{abstract}
A hybrid-heating microwave oven provides the energy to heat small 10-gram samples of spent metal tritide storage bed material to release tenaciously held decay product ${ }^{3} \mathrm{He}$. Complete mass balance procedures require direct measurement of added or produced gases on a tritide bed, and over $1100^{\circ} \mathrm{C}$ is necessary to release deep trapped ${ }^{3} \mathrm{He}$. The decomposition of non-radioactive $\mathrm{CaCO}_{3}$ and the quantitative measurement of $\mathrm{CO}_{2}$ within $3 \%$ of stoichiometry demonstrate the capabilities of the apparatus to capture generated (released) gases.
\end{abstract}

\section{BACKGROUND}

Savannah River National Laboratory (SRNL) is developing a modern gas assay method for spent tritium storage beds for Sandia National Laboratory/Ca. Currently, helium from tritium decay remains trapped after delivery of the stored gas, so a complete characterization of the storage bed is not obtained from the delivered gases. A technique is under development that releases the helium content from the spent bed material in a way that allows quantitative measurement with the same accuracy as that measured for other gas species. SRNL has successfully identified the right materials of construction and process configuration to heat small samples of spent palladium storage bed material in an inexpensive commercial "hybrid" microwave oven in a controlled manner to a high enough temperature to cause the desired effect of releasing the helium. ${ }^{1}$ After a few successful tests using zirconia as a surrogate storage bed material, the first test using representative (cold) palladium storage bed material was performed. A temperature of $1200^{\circ} \mathrm{C}$ obtained in a few minutes after starting the microwave oven, and controlled for over half an hour.

It was then desirable to produce a dry gas in the unit and measure the moles of gas produced to demonstrate the ability to quantify a non-condensable gas produced in the system. The decomposition of $\mathrm{CaCO}_{3}$ to $\mathrm{CO}_{2}$ was used to test the system without using tritium contaminated samples. This proved to be quite acceptable since the measured number of moles of $\mathrm{CO}_{2}$ matched the calculated number of moles based on stoichiometry to within $3 \%$.

\section{SYSTEM CONFIGURATION}

The hybrid microwave unit for gas measurement consists of the microwave oven, the susceptor unit and insulation, the plasma shield, the cooling fin(s), the charge tube, and the gas manifold. A thermocouple, vacuum pump, pressure gauge, gas supply, and calibrated bomb tank are connected to the gas manifold. Flexible hoses between the manifold and the vacuum pump, pressure gauge, and calibrated bomb tank allow freedom of movement of the part of the manifold that holds the charge tube. Fig. 1 shows a picture of the prototype microwave oven with the charge tube inserted into the unit. A 7.4-inch tall charge tube reaches 2.25 inches into the susceptor encasement, which is 5 inches above the bottom of the microwave cavity.

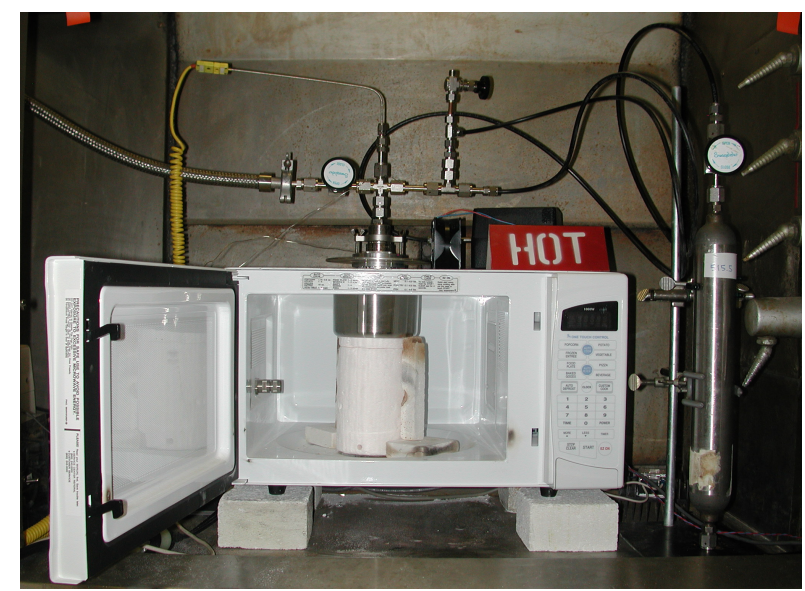

Fig.1. Prototype Microwave Oven

The charge tube is made of a 1" OD quartz tube and is sealed by an ultra-Torr $\AA$ fitting at the top. A thermocouple extends down through the center of the tube that has an alumina filter attached to it to shield the coupling at the top from the heat shine below. The single fin with fan keeps the temperature at the fitting below $50^{\circ} \mathrm{C}$. If the fan fails, the coupling temperature reaches almost $80^{\circ} \mathrm{C}$ at an operating temperature of $1200^{\circ} \mathrm{C}$ in the charge tube. The maximum temperature for the o-ring in the ultra-Torr Seal ${ }^{\circledR}$ fitting is $204^{\circ} \mathrm{C}$. Fig. 2 shows the charge tube fully removed above the microwave oven. 
The microwave susceptor is 200 grams of granular $\mathrm{SiC}$ (silicon carbide) encased in a 6" tall annular quartz encasement around a 1" center hole where the charge tube slides in and out. The 2" OD quartz encasement is set in a 2" ID x 4" OD x 8" tall alumina insulation tube that has a 1 " thick bottom to it.

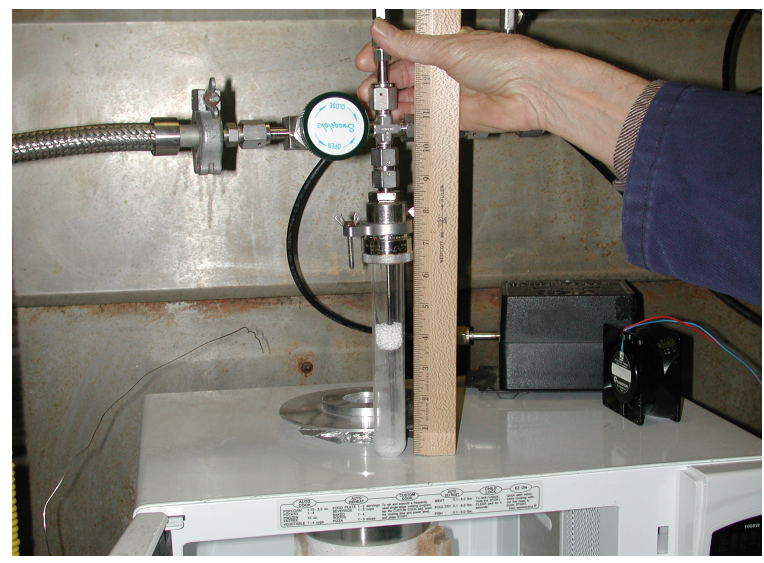

Fig.2 Charge tube with alumina foam filter

Once the quartz encasement is inserted into the insulation tube, a 1" thick alumina insulation ring is placed on top of the quartz encasement and some alumina wool is stuffed above that to ensure no heat shine reaches the metal above. The 3" tall stainless steel plasma shield goes around the outside of the insulation and is positioned against the top of the microwave oven cavity. The bottom of the shield is about $3 / 8$ " below the top of the $\mathrm{SiC}$ in the susceptor unit. These pieces are shown in Fig.3.

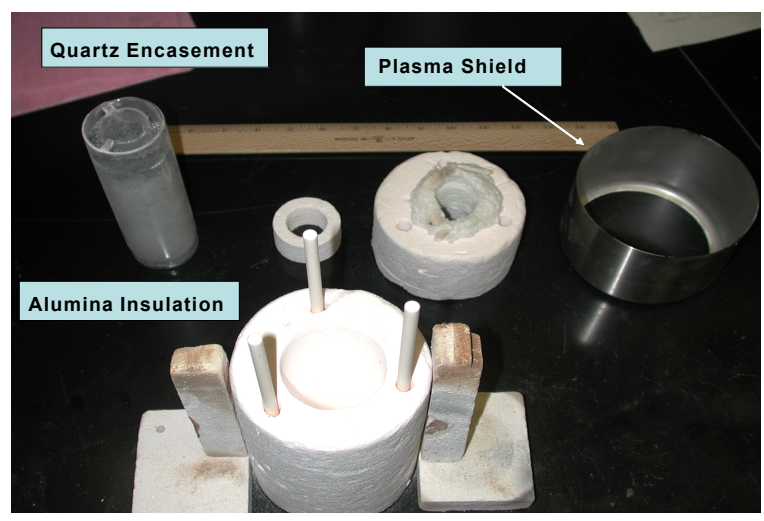

Fig.3 Plasma Shield and Quartz Encasement

The plasma shield extends down from the top of the microwave cavity to about $1 / 4$ " below the top of the susceptor. The purpose of this shield is to reduce the direct impingement of microwaves into the charge tube to prevent a plasma from forming inside the charge tube at low pressures. A plasma causes uncontrolled rapid heating of the tube and its contents. Without the plasma shield, a plasma can form at pressures from 3 Torr up to 80 Torr. With the plasma shield, a plasma can only form at pressures less than 9 Torr. As a result, the heating process can be started with about 15 Torr of an inert gas.

\section{SYSTEM CONTROL}

\section{III.A. Microwave Heating Control}

The magnetron produces the microwaves in the oven. Control of the magnetron was accomplished by inserting an ON/OFF relay in the line going to the step up transformer prior to the magnetron. Automatic computer control of the relay was based on either the pyrometer temperature reading or the charge tube thermocouple temperature reading versus an operator set point. Manual computer control of the relay was based on a percent output inputted by the operator. The cycle time is 32 seconds, so a $50 \%$ output would produce 16 seconds $\mathrm{ON}$, then 16 seconds OFF and so on. To operate the oven, the operator would still have to enter a time on the oven front panel and press the start button. All original safety interlocks on the oven remained in use, which includes the door interlock and the cavity over-temperature interlock. Both interlocks shut off the oven.

\section{III.B. Temperature Response}

Using the magnetron control scheme described above, the temperature of the sample in the charge tube rapidly heats to process temperature and remains at temperature for the duration of the measurement. Fig. 4 shows the pyrometer (IR2) reading for a process run, and the pressure increase in the charge tube for an initial pressure of 400 Torr.

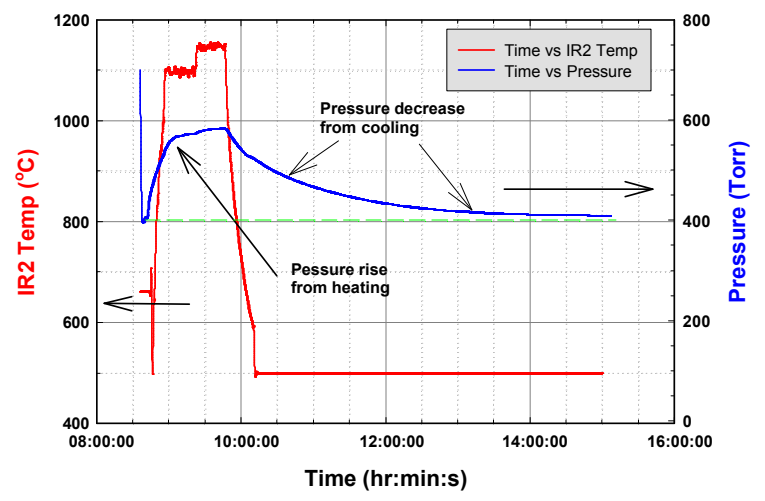

Fig. 4 Pressure rise due to gas heating

The sample temperature rose to $1100^{\circ} \mathrm{C}$, remained for about 30 minutes, and was increased to $1150^{\circ} \mathrm{C}$ for 
another 30 minutes. Power was turned off and the system cooled for about 4 hours. Notice the pyrometer does not begin to read until $600^{\circ} \mathrm{C}$, necessitating the use of an internal thermocouple to measure the full range of temperatures of the sample.

While the sample is at temperature, there is a good bit of radiant "shine" emanating in all directions. The alumina foam filter (Fig.2) attached to the internal thermocouple effectively blocks the shine and helps maintain the temperature of the ultraTorr Seal ${ }^{\circledR}$ o-ring connection to the quartz tube at or near ambient. Fig. 5 shows the IR2 pyrometer reading during a process run again at $1100-1150^{\circ} \mathrm{C}$, along with the measured temperatures of the upper and lower parts of the o-ring connection. The heatsink and instrument fan help remove the heat, maintaining 29 to $33^{\circ} \mathrm{C}$ at the o-ring.

The temperature rise is rapid for these process runs. The observed increase based on the pyrometer is about $80^{\circ} \mathrm{C}$ per minute from about 500 to $1100^{\circ} \mathrm{C}$. The temperature control using the $\mathrm{ON} / \mathrm{OFF}$ power control of the magnetron is within $\pm 5^{\circ} \mathrm{C}$ at $1100^{\circ} \mathrm{C}$.

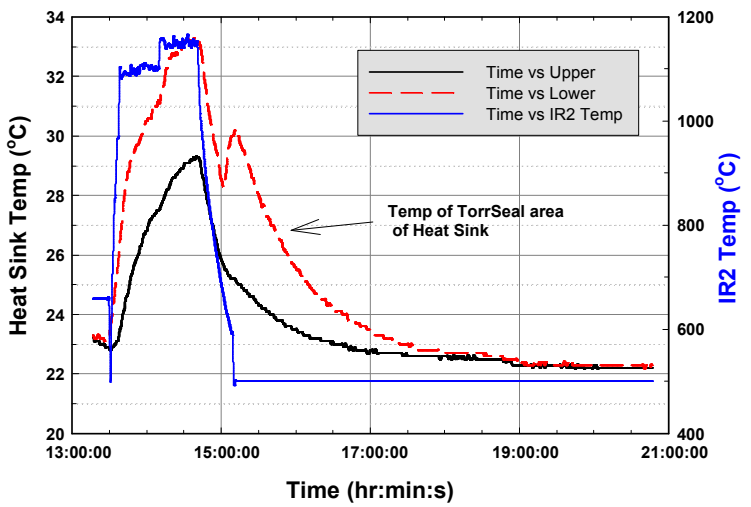

Fig.5 Temperature range of o-ring

\section{MEASUREMENT OF A GAS}

The quantitative measurement of a gas requires the knowledge of the total system volume, the charge volume, the hot volume, the initial cold temperature, the initial pressure, the final pressure, the final cold temperature, and the hot temperature. The total system volume and the hot volume are calibrated once and are constants throughout successive runs.

\section{IV.A. Hot Volume Determination}

During operation, part of the system is heated to about $1200^{\circ} \mathrm{C}$ with a temperature gradient to the temperature of the rest of the system, which is near ambient temperature. For purposes of determining moles of gas, the system will be described mathematically as having two distinct temperature zones that are the hot volume $V h$, and the cold volume, $V c$, which is the measured manifold temperature.

Using the Ideal Gas Law,

$$
\frac{P_{1} V_{1}}{T_{1}}=\frac{P_{2} V_{2}}{T_{2}}
$$

Eq. (1) can be divided into hot and cold volumes

$$
m=\frac{P_{1}}{P_{2}}=\frac{\left(\frac{V_{C}}{T_{O}}+\frac{V_{H}}{T_{O}}\right)}{\left(\frac{V_{C}}{T_{O}}+\frac{V_{H}}{T_{H}}\right)}
$$

where $V_{C}$ is the cold volume, $V_{H}$ is the hot volume, $T_{O}$ is the cold temperature, $T_{H}$ is the hot temperature, $P_{l}$ is the pressure when the charge tube is at the hot temperature, and $P_{2}$ is the pressure when the charge tube is at the cold temperature. Cold temperature is usually the room, or starting temperature. Solving for the hot volume,

$$
V_{H}=\frac{V_{T} T_{H}(m-1)}{m\left(T_{H}-T_{O}\right)}
$$

where $\boldsymbol{m}$ is the ratio of the system pressure at the hot temperature to the pressure at the cold temperature (Eq.2), and $V_{T}$ is the total volume, $V_{C}+V_{H}$. To determine the hot volume, a known $\mathrm{ZrO}_{2}$ charge and an initial pressure of $\mathrm{N}_{2}$ at room temperature was heated to $1200^{\circ} \mathrm{C}$ and obtained steady state pressure. This was repeated for several starting pressures. The data are in Table I.

TABLE I. Hot Volume

\begin{tabular}{cc}
\hline $\mathbf{P}_{\mathbf{1}}$ & $\boldsymbol{V} \boldsymbol{h}$ \\
$\mathbf{( T o r r )}$ & $(\mathbf{m L})$ \\
\hline 269 & 53.9 \\
338 & 54.1 \\
378 & 54.7 \\
451 & 54.2 \\
489 & 52.0 \\
629 & 52.6 \\
733 & 51.7 \\
\hline Average & $\mathbf{5 3 . 3}$ \\
\hline
\end{tabular}

\section{IV.B. Gas Production Determination}

The decomposition of $\mathrm{CaCO}_{3}$ to $\mathrm{CO}_{2}$ was used to demonstrate that a gas can be produced in the system 
and quantitatively collected. A total of eight runs were performed for determining gas production. In each run, various amounts of $\mathrm{ZrO}_{2}$ and $\mathrm{CaCO}_{3}$ were charged to the tube. The system was evacuated and purged with $\mathrm{N}_{2}$ three times. The charge volume was determined, and the system was charged with enough $\mathrm{N}_{2}$ to raise the pressure to 15 Torr to prevent plasma from forming during initial heating. The system was heated to $1200^{\circ} \mathrm{C}$ and held there until the pressure came to steady state. Then the data were collected to determine the number of moles of $\mathrm{CO}_{2}$ formed from the $\mathrm{CaCO}_{3}$ both by chemical stoichiometry and by the ideal gas law, and are in Table II.

Table II. $\mathrm{CaCO}_{3}$ Decomposition Data

\begin{tabular}{cccccc}
\hline \# & $\begin{array}{c}\mathbf{C a C O}_{\mathbf{3}} \\
\mathbf{g m s}\end{array}$ & $\begin{array}{c}\mathbf{P}_{\mathbf{1}} \\
\text { Torr }\end{array}$ & $\begin{array}{c}\mathbf{C O}_{\mathbf{2}} \\
\text { calc }\end{array}$ & $\begin{array}{c}\mathbf{C O}_{\mathbf{2}} \\
\text { meas }\end{array}$ & \% \\
\hline 1 & 1.575 & 495.2 & 0.0158 & 0.0157 & -0.28 \\
2 & 1.568 & 496.2 & 0.0157 & 0.0157 & -0.22 \\
3 & 1.575 & 498.8 & 0.0158 & 0.0158 & 0.27 \\
4 & 1.580 & 504.1 & 0.0158 & 0.0160 & 0.95 \\
5 & 1.574 & 510.2 & 0.0157 & 0.0161 & 2.52 \\
6 & 0.926 & 314.2 & 0.009 & 0.001 & 5.57 \\
7 & 0.926 & 314.0 & 0.009 & 0.001 & 5.32 \\
8 & 2.235 & 705.0 & 0.022 & 0.023 & 0.99 \\
\hline
\end{tabular}

The error results were analyzed against final system pressure and volume of inert charge. Neglecting the data of runs 6 and 7 (final pressure around 300 Torr seemed to have an issue), the measured moles of $\mathrm{CO}_{2}$ were accurate at worst to within about $3 \%$. The data were independent of the volume of the charge.

\section{CONCLUSIONS}

- The hybrid microwave system is capable of heating samples to greater than $1200^{\circ} \mathrm{C}$.

- The quartz components can withstand $1200^{\circ} \mathrm{C}$ for at least several hours without any apparent change. (Quartz annealing temp: $1215^{\circ} \mathrm{C}$; softening temp: $1885^{\circ} \mathrm{C}$ )

- The quartz components in the susceptor remain usable after 26 runs.

- The unit can be controlled to prevent plasma from occurring.

- The unit can control the temperature $\pm 25^{\circ} \mathrm{C}$ at $300^{\circ} \mathrm{C}$ and $\pm 5^{\circ} \mathrm{C}$ at $1200^{\circ} \mathrm{C}$.
- The system can measure non-condensable gases to within less than $3 \%$ error when the final pressure is 490 to at least 700 Torr. Note that the o-ring was tested at the high pressure test lab and held pressure up to $50 \mathrm{psig}$ at room temperature. The expectation is to run the unit where the maximum expected pressure is below 1000 Torr.

- Because of the massive amount of insulation around the charge tube and susceptor, the oven cavity temperature becomes warm (about $50^{\circ} \mathrm{C}$ ), but does not follow the temperature of the charge tube.

The system protocol described here is but one of many that can be programmed to use the hybrid-heating microwave oven. For example, intermediate temperature stops can be included to soak a sample at temperature before continuing to a higher temperature. Also, the sample gas released can be evaluated after the charge tube and sample return to ambient, removing the need to calculate a "hot volume". However, we have demonstrated that the division of the manifold into a hot section and a cold section does return reasonable results, to within about $3 \%$ once the calibration curve has been obtained.

\section{ACKNOWLEDGEMENT}

RTW acknowledges William Curtis (Curt) Sexton of the Glass Development Laboratory at SRNL for support for all quartz glass needs for this project.

This document was prepared in conjunction with work accomplished under Contract No. DE-AC09$96 S R 18500$ with the U.S. Department of Energy.

\section{REFERENCES}

1. G.C. ABEL, L.K. MATSON, R.H. STEINMEYER, R.C. BOWMAN, JR., B.M. OLIVER, "Helium release from aged palladium tritide," Physical Review B, Vol. 41, No. 2 (19901) $1220-1223$. 